\title{
Review Article \\ ROLE OF OSTEOPONTIN IN BOVINES AND THEIR ASSOCIATION WITH DIFFERENT TRAITS: A REVIEW
}

\section{KUMAR SUCHIT1*, MUKHERJEE ANUPAMA ${ }^{1}$, KUMAR SUNIL ${ }^{2}$, YADAV ALOK KUMAR ${ }^{1}$, AND ANAND KUMAR N. ${ }^{1}$}

${ }^{1}$ Animal Genetics and Breeding Division, ICAR-National Dairy Research Institute, Karnal, 132001, Haryana, India.

${ }^{2}$ Animal Physiology Division, ICAR-National Dairy Research Institute, Karnal, 132001, Haryana, India

*Corresponding Author: Email - suchitkumar636@gmail.com

\section{Received: March 30, 2018; Revised: April 03, 2018; Accepted: April 05, 2018; Published: April 15, 2018}

\begin{abstract}
Osteopontin is a phosphorylated glycoprotein which forms an important component of the mineralized extracellular phosphorylated glycoproteins which plays a vital role in mineralized extracellular matrices of bones and teeth. It has a multifunctional protein found in various types of tissues and body fluids with highest concentrations found in milk. Comparative sequence analysis of the bovine OPN with various species has revealed both conserved and non-conserved sequences. This gene is located on BTA 6 comprising of 7 exons. OPN gene is involved in cell-mediated immune responses, inflammation and cell attachment. Osteopontin gene has important roles in growth, production and reproduction of the animals, and is also known to be associated with body weight, stillbirth and dystocia in bovines. OPN is reported to up regulate and promote the expression and secretion of Th1 cytokines. Polymorphism in this gene makes it a probable candidate for improving genetic progress in cattle breeding.
\end{abstract}

Keywords- Osteopontin (OPN gene), Polymorphism, Association, Stillbirth, Dystocia.

Citation: Kumar Suchit, et al., (2018) Role of Osteopontin in Bovines and Their Association with Different Traits: A Review. International Journal of Genetics, ISSN: 0975- 2862 \& E-ISSN: 0975-9158, Volume 10, Issue 3, pp.-370-372. DOl: http://dx.doi.org/10.9735/0975-2862.10.3.370-372

Copyright: Copyright@2018 Kumar Suchit, et al., This is an open-access article distributed under the terms of the Creative Commons Attribution License, which permits unrestricted use, distribution and reproduction in any medium, provided the original author and source are credited.

\section{Introduction}

Osteopontin (OPN) is an acidic highly phosphorylated glycoprotein that contains the integrin binding Arge-Glye-Asp (RGD) and SVVYGLR sequences. OPN is found indifferent types of tissues and body secretions [1] with highest concentrations in milk [2]. OPN is a chief component in several of physiological processes such as inhibition of ectopic calcification, bone remodeling and immune modulatory functions $[3,1,4]$, indicating that milk OPN could be an important factor in the development of the immune system of infants. Milk OPN is highly resistant to adverse conditions and heat treatment at $90{ }^{\circ} \mathrm{C}$ does not bear any effect on the post-translational modifications of the protein [5]. Osteopontin protein (OPN) is also known by other names such as Secreted phosphoprotein (SPP1), bone sialoprotein I (BSP-1), and early T-lymphocyte activation (ETA-1). SPP1 was first discovered in 1986 in osteoblasts. The name "osteopontin" is attributed to potential of the bone protein to serve as a bridge between cells and hydroxyapatite through RGD and polyaspartic acid motifs discovered in the primary sequence of the protein [6]. SPP1 is produced by both immune and nonimmune cells such as osteoclasts, smooth muscle cells and epithelial cells [7]. The primary immune sources of OPN are activated macrophages [8] and activated T cells. The protein is also found in milk, plasma and urine. The SPP1 is highly negative charged, protein that lacks an extensive secondary structure. Comparative sequence analysis of the bovine OPN CDNA with various species has revealed both conserved and non-conserved sequences. For example, both the bovine and ovine sequences have a common 22-AA gap compared to all other examined species [9]. Numerous whole-genome scans in cattle have identified QTL governing milk production traits on BTA 6 nearby OPN gene [10]. Positioned a QTL affecting milk production traits to an interval of $420 \mathrm{~kb}$ between the genes ABCG2 [ATP binding cassette, subfamily G (WHITE), member 2] and LAP3 (leucineamino peptidase 3) on chromosome 6 in bovines. This narrow region harbors only 6 genes, including OPN, which comprises of seven exons measuring $86,68,39,81,42,303$ and 748 bp in length respectively.

Structure and expression - comparison of human and bovine milk osteopontin

Human OPN is comprised of 298 amino acids whereas the bovine form contains only 262 residues. Bovine and human OPN sequences reveal 182 identical amino acids (61\%) and an additional 44 residues retain high structural similarity. OPN is encoded by a single copy gene, and during transcription human OPN can undergo alternative splicing generating two splice variants each lacking a single exon [11] In addition, OPN translation product can be modified by especially phosphorylation, 0-glycosylation and proteolytic processing [12] leading to the existence of numerous isoforms. OPN functionally similar OPN iso forms are cell and tissue-specific and OPN expressed by different cell-types or under different conditions have been shown to be functionally different $[13,14]$. OPN is highly phosphorylated in milk and contains 25 phosphates distributed over 36 potential sites in the human milk OPN $[14,15]$ and 22 phosphates and 28 potential sites in bovine milk OPN [16]. Bovine milk OPN contains three 0-glycosylated threonine residues close to the integrin binding motifs [5].

\section{Role of osteopontin in milk}

OPN is secreted by many tissues with highest concentration in milk. Human milk contains $-138 \mathrm{mg} / \mathrm{mL}$ and bovine milk contains $-18 \mathrm{mg} / \mathrm{mL}$ [2]. The high level of OPN expression in human milk persists throughout the lactation period and possesses known cytokine-like properties [17].

\section{Role in mammary gland}

OPN were reported to be involved in mammary gland development and 
differentiation, as transgenic mice expressing OPN antisense-RNA have severe lactation deficiency and display a lack of mammary alveolar structures [18]. In contrast to these transgenic mice, OPN knockout mice are both fertile, lactating and produce a normal litter size [19]. Milk OPN is a very acidic protein due to a high degree of negatively charged amino acids and the many phosphorylations decorating the protein. This intrinsic property allows OPN to bind and form soluble complexes with calcium ions, which together with especially the caseins, could inhibit unintentional precipitation of amorphous calcium phosphate in milk [20-22].

\section{Role in immunity}

The OPN expression can induce Th1 cytokine interleukin- 12 and inhibit the production of the Th2 cytokineas well asinterleukin-10, therefore it plays a key role in the cytokinin regulation of the Th1/Th2 balanced immune response. Phosphorylation of OPN is necessary for the induction of interleukin-12 expression. The Th1 response generation is essential for the removing of intracellular pathogens and OPN-deficient mice are more susceptible to both viral and bacterial infections than wild type. Thus, breast milk OPN protects infants against infections by inducing a Th1 immune response. This suggests that OPN in milk plays a more direct role in the immune defence by interacting directly with invading pathogens. OPN can form complexes with lactoferrin, lactoperoxidase and IgM through electrostatic or affinity interactions [23]. It had been hypothesised to act as a transporter of these immune modulating and antimicrobial proteins to their site of action and also protect them from proteolysis [23,24].

\section{General comparison of OPN of Bos taurus and Bubalus bubalis}

OPN is composed of about 300 amino acids in general (294 in Mus musculus, 314 in Homo sapiens, 278 in Bos Taurus, 280 in Bubalus bubalis and 303 in Sus scrofa). Comparison between bubaline OPN and taurine OPN revealed 12 nucleotide differences in the exonic region (two in exon 1, seven in exon 6 and three in exon 7) as well as complete homology in exons 2-5. The bubaline OPN had insertion of two amino acids at positions 94 (Aspartic acid) and 227 (Asparagine), making a total of 280 amino acids [25]

\section{Position and general description about the gene}

The bovine and ovine sequences have a 22-AA gap compared with all other examined species [9]. QTL affecting milk production traits on BTA 6 close to OPN gene location were identified by whole-genome scans in cattle $[26,10]$. Olsen et al.[10] positioned a QTL affecting milk production traits to an interval of $420 \mathrm{~kb}$ between the genes ABCG2 and LAP3. This narrow region harbors only 6 genes, including OPN. Osteopontin is negative charged, extracellular matrix protein that lacks an extensive secondary structure. There are seven exons in this gene such as $86,68,39,81,42,303$ and 748 bp in length.

\section{Polymorphisms in OPN gene in cattle}

OPN gene, a positional candidate for the statistically most significant of the identified QTL. Leonard, et al., reported nine mutations and only genotypes for the OPN3907 indel were concordant with the QTL genotypes of eight bulls that were established by segregation analysis [9]. In introns 4 (C/T) polymorphism was detected from 1362 bulls obtained from Cooperative Dairy DNA Repository (CDDR) and from 214 cows from the herd of University of Wisconsin (UW) in United States. The observed alleles consisted of 9 or 10 consecutive thymidine base pairs on the sense strand and an indel polymorphism (T9/T10) was reported to be highly associated with beef production traits [27]. Khatib et al. [28] reported the additive effects of OPN C>T polymorphism in 931 samples of in Holstein cattle significantly associated with fat percentage, protein percentage and fat yield. High OPN polymorphism was observed in panel animals of Hereford ( $n=23$ ), Limousine $(n=24)$, Polish Holstein-Fresian ( $n=28)$ and Polish Red $(n=23)$ cattle. In South and East Anatonian Red cattle polymorphism reported at 8514C>T SNP in intron 4.

\section{Polymorphisms in buffaloes}

Characterized the OPN in buffalo (Bubalus bubalis) and sequenced OPN gene from the genomic DNA as well as from the CDNA of buffalo mammary gland [25]. A comparative analysis of the buffalo OPN gene and the presumed protein sequence with $B$. taurus as reference sequence (AY878328) was studied and they observed polymorphisms in 24 sequences of OPN gene among six different breeds of buffalo. They were detected a total of six SNP such as five in intronic and one in the upstream region. The SNP of buffalo in the upstream region OPN was the same as reported by Schnabel, et al., (2005) in B. taurus. All the SNPs in the intronic region were transitions.

\section{Association Studies with Different Traits Production trait}

Khatib, et al. [28] studied the association of bovine Osteopontin genes with milk composition in Holstein Cattle Populations and reported the association of Osteopontin variants with milk production traits. In the population, 891 cows were genotyped for OPN gene and the C/T polymorphism reported in the CDDR population. Additive effects were significant for fat percentage, protein percentage and fat yield in population.

Leonard, et al., [9] reported effects of the Osteopontin gene variants on milk production traits in dairy cattle. A single nucleotide polymorphism in intron 4 (C/T) was detected in 1362 bulls and 214 cows. For the population, the $C$ allele was associated with an increase in protein percentage and fat percentage.

Boleckova, et al. [29] reported association of polymorphisms with milk production traits in Czech Fleckvieh cattle. The polymorphism in osteopontin was significantly associated with milk protein percentage.

Kowalewska-Luczak [30] studied genetic polymorphisms of OPN genes in 181 Jersey cattle. The minor allele frequencies of osteopontin were found to be OPN $T / C 0.22$ and OPN G/T 0.38. No associations were observed between the singlenucleotide polymorphisms in analysed loci and the milk performance traits; however, the findings showed some tendencies towards reaching lower or higher values of a given trait by an individual of a given genotype.

Salehi, et al., [31] reported association of bovine osteopontin (OPN) gene with milk production traits in Iranian Holstein Bulls. A total of 100 Semen samples from progeny tested Iranian Holstein bull's were collected. Allele frequencies of $T$ and $C$ were $0.59 \pm 0.03$ and $0.41 \pm 0.03$, respectively. However, $C C$ genotype had higher fat yield $(6.02 \mathrm{~kg})$, fat and protein percent $(-0.035,-0.04)$ but lower milk yield than TT genotype (157.5 kg VS $173.95 \mathrm{~kg}$ ).

Pasandideh, et al. [32] reported associations of single nucleotide SNP C>T at position 8514 in OPN gene with milk production and composition. A total of 398 Iranian Holstein cows were genotyped through polymerase chain reaction and restriction fragment length polymorphism (PCR-RFLP). There were significant associations of polymorphism at3359C $>$ T genotypes in OPN gene with milk yield percentage $(P<0.05)$ and protein percentage $(P<0.01)$.

\section{Association with growth and weaning weight}

OPN3907 polymorphism was segregating in GPE7 and GPE8 with the T9 allele as the minor allele in both populations. The Osteopontin genotype was associated with measures of weight gain in GPE7, including yearling weight, live weight at slaughter and weaning weight. The T10/T10 homozygotes were heavier weights than the T9/T10 heterozygotes. Likely in GPE8, the T10/T10 homozygotes were significantly associated with weight gain, including higher yearling weight, higher live weight at slaughter, and higher post weaning ADG, compared with the T9/T10 heterozygotes. The SPP1 marker was associated with yearling weight $(P=0.034)$, live weight at slaughter $(P=0.011)$, and post weaning $(P=0.015)[27]$ OPN3907 polymorphism was Significant additive associations of SPP1 were detected for animals of single births for birth weight single birth (BWT-S), weaning weight $205 \mathrm{~d}$ single birth (WW205- S), and yearling weight $365 \mathrm{~d}$ single birth (YW365-S) with effects of $1.14,5.16$, and $7.89 \mathrm{~kg}$, respectively as well as significant association of the SPP1 marker with birth weight $(P<0.006)$, weaning weight $(P<0.007)$, and yearling weight $(P<0.003)$ in USMARC[33].

\section{Association with stillbirth and dystocia}

The most significant results were found for BTA6, where five SNPs were associated with dystocia. These were marker numbers 220 (BTA-75651), 275 (BTA-75979), 276 (rs29026959), 285 (BTA-75776) and 322 TA-107931). The QTL for dystocia close to marker 275 also affected Still birth. The region around marker 
number 285 (BTA-75776) contains at least six known genes; osteopontin (OPN)], matrix extracellular phosphoglycoprotein (MEPE), integrin-binding sialo protein (IBSP), leucine amino peptidase 3 (LAP3), mediator complex subunit 28 (MED28) and non-SMC condensing I complex, subunit G (NCAPG). The most significant result was found on BTA6. This chromosome was found to contain one QTL affecting both SBdir and DYSdir close to marker 275 (BTA-75979) or 276 (rs2902695), and a second QTL affecting DYSdir only, close to marker 285 (BTA75776). For DYSdir, the most significant position obtained by LDLA was close to BTA-75776 (i.e. marker 285), [27].

\section{Conclusion}

Osteopontin is one of the most important glycoprotein of SIBLING family. OPN is complex protein expressed in many tissues and body fluids, with the highest concentrations in milk. OPN is involved in normal physiological processes and the protein exists in many different isoforms resulting from alternative splicing and post-translational modification. It has several biological functions in animals as well as human. It controls growth, production, reproduction and immunity. While some studies suggested that OPN itself affects milk protein percentage, further investigation of the OPN gene, including upstream and downstream control regions, is needed to explore molecular mechanisms causing the QTL effects. SPP1 gene is a good candidate gene for many traits (Stillbirth and dystocia, protein percentage of milk, twinning rate etc). So, it has great potential to be used in marker assisted selection and hence in improving genetic progress in cattle breeding.

Application of review: Role of osteopontin in bovines and their association with different traits.

Review Category: Animal Genetics and Breeding

Abbreviations: OPN: Osteopontin

Acknowledgement / Funding: Author thankful to ICAR-National Dairy Research Institute, Karnal, 132001, Haryana

Research Guide or Chairperson of research: Dr. Anupama Mukherjee Institute: ICAR-National Dairy Research Institute, Karnal, 132001, Haryana

Author Contributions: All author equally contributed

Author statement: All authors read, reviewed, agree and approved the final manuscript

\section{Conflict of Interest: None declared}

Ethical approval: This article does not contain any studies with human participants or animals performed by any of the authors.

\section{References}

[1] Sodek J., Ganss B. and McKee M. D. (2000) Biology and Medicine, 11, 279-303.

[2] Schack L., Lange A., Kelsen J., Agnholt J., Christensen B. and Petersen T. E. (2009) Journal of Dairy Science, 92, 5378-5385.

[3] Anborgh P. H., Wilson S. M., Tuck A. B., Winquist E., Schmidt N. and Hart R. (2009) Clinical Chemistry, 55, 895-903.

[4] Wang K. X. and Denhardt D. T. (2008) Cytokine and Growth Factor Reviews, 19, 333-345.

[5] Sorensen E. S., Hojrup P. and Petersen T. E. (1995) Protein Science, 4, 2040-2049.

[6] Oldberg A., Franzen A. and Heingard D. (1986) Proc Natl Acad Sci USA., 83, 8819-8823.

[7] Denhardt D.T. and Guo X. (1993) Experimental Biology, 7,1475-1482.

[8] Atkins K., Berry J. E., Zhang W. Z., Harris J. F., Chambers A. F., Simpson
R. U. and Somerman M. J. (1998) Journal of Cell Physiololy, 175, 229-237.

[9] Leonard S., Khatib H., Schutzkus V., Chang Y.M. and Maltecca C. (2005) Journal of Dairy Science, 88,4083-4086.

[10] Olsen H. G., Lien S., Svendsen M., Nilsen H. and Roseth A. (2004) Genet. Sel. Evol., 33, 543-548

[11] Young M. F., Kerr J. M., Termine J. D., Wewer U. M., Wang M. G. and McBride O. W. (1990) Genomics, 7, 491-502.

[12] Qin C., Baba 0. \& Butler W. T. (2004) Biology and Medicine, 15, 126-136.

[13] Christensen B., Kazanecki C. C., Petersen T. E., Rittling S. R., Denhardt D. T. and Sorensen E. S. (2007) Journal of Biological Chemistry, 282, 1946319472.

[14] Christensen B., Klaning E., Nielsen M. S., Andersen M. H., \& Sørensen E. S. (2012) Journal of Biological Chemistry, 287,3788-3797.

[15] Christensen B., Nielsen M. S., Haselmann K. F., Petersen T. E. and Sorensen E. S. (2005) Biochemical Journal, 390, 285-292.

[16] Boskey A. L., Christensen B., Taleb H. and Sorensen E. S. (2012) Biochemical and Biophysical Research Communications, 419, 333-338.

[17] Nagatomo T., Ohga S., Takada H., Nomura A., Hikino S. and Imura M. (2004) Clinical and Experimental Immunology, 138, 47-53.

[18] Nemir M., Bhattacharyya D., Li X., Singh K., Mukherjee A. B. \& Mukherjee B. B. (2000) Journal of Biological Chemistry, 275, 969-976.

[19] Rittling S. R., Matsumoto H. N., McKee M. D., Nanci A., An X. R., Novick K. E. (1998) Journal of Bone and Mineral Research, 13, 1101-1111.

[20] Holt C., Lenton S., Nylander T., Sorensen E. S. and Teixeira S. C. M. (2014) Journal of Structural Biology, 185, 383-396.

[21] Holt C., Sorensen E. S. and Clegg R. A. (2009) FEBS Journal, 276, 23082323.

[22] Klaning E., Christensen B., Sorensen E. S., Vorup-Jensen T. and Jensen J. K. (2014) Bone, 66, 90-95.

[23] Azuma N., Maeta A., Fukuchi K. \& Kanno C. (2006) International Dairy Journal, 16, 370-378.

[24] Yamniuk A. P., Burling H. and Vogel H. J. (2009) Molecular Immunology, 46, 2395-2402.

[25] Tantia M. S., Mishra B., Bharani K., Mishra B. P., Kataria R. S., Mukesh M. and Vijh R. K. (2008) The Animal Consortium, 2(7), 987-990.

[26] Ashwell M., Heyen D., Sonstegard T., Van Tassell C., Da Y., VanRaden P., Ron M., Weller J. \& Lewin H. (2004) Journal of Dairy Science, 87, 468-75.

[27] White S. N., Casas E., Allan M. F., Keele J. W., Snelling W. M., Wheeler T. L., Shackelford S. D., Koohmaraie M. and Smith T. P. L. (2007) Journal of Animal Science, 85,1-10.

[28] Khatib H., Zaitoun I., Wiebelhaus-Finger J., Chang Y.M. and Rosa G.J.M. (2007b) Journal of Dairy Science, 90,2966-2970.

[29] Boleckova J., Matejickova J., Stipkova M., Kyselova J. and Barton L. (2012) Journal of Animal Science, 57 (2), 45-53.

[30] Kowalewska- Luczak I. and Hanna K. (2013) Turk Journal Vet Animal Science, 37, 631-635.

[31] Salehi A., khadijeh N., Mahdi A., Mohammad B. S. and Rohoallah S. (2015) Iran Journal of Biotech, 13(1), 1092.

[32] Pasandideh M., Mohammadabadi M.R., Esmailizadeh A.K. and Tarang A. (2015) Journal of Animal Science, 60 (3), 97-104.

[33] Allan M. F., Thallman R. M., Cushman R. A., Echternkamp S. E., White S. N., Kuehn L. A., Casas E. and Smith T. P. L. (2007) Journal of Animal Science, 85,341-347. 